\title{
Erratum to: Revision and necessary correction of the long-term temperature series of Hohenpeissenberg, 1781-2006
}

\section{P. Winkler}

Published online: 29 April 2010

(C) Springer-Verlag 2010

Erratum to: Theor Appl Climatol (2009) 98:259-268

DOI 10.1007/s00704-009-0108-y

On page 266, the formula, which was used in Bavaria to calculate the daily mean between 1879 and 1900 was cited wrongly. Instead of $T_{m}=\left(T_{8}+T_{14}+T_{20}\right) / 3$ it should read $T_{m}=\left(T_{8}+T_{14}+T_{20}+T_{\min }\right) / 4$ (Erk 1883). This latter formula gives a too low daily mean. The conclusions drawn and the correction applied (Table in Section 6 and Fig. 5) are unaffected.

\section{Reference}

Erk F (1883) Die Bestimmung wahrer Tagesmittel der Temperatur unter besonderer Berücksichtigung langjähriger Beobachtungen von München, Abhandl. der Akademie d. Wiss. München, 1883, $178-229$

The online version of the original article can be found at http://dx.doi. org/10.1007/s00704-009-0108-y.

P. Winkler $(\bowtie)$

Hechenbergstraße 9,

82362 Weilheim, Germany

e-mail: pu_winkler@t-online.de 